\title{
Acoustic measurements of zooplankton using a dual frequency echo sounder
}

\author{
K. Miyashita*, I. Aoki** \\ Ocean Research Institute, The University of Tokyo, Minamidai, Nakano, Tokyo 164, Japan
}

\begin{abstract}
Two methods for acoustic estimation of zooplankton abundance using the difference in volume back-scattering strength (SV) at 2 frequencies between 38 and $200 \mathrm{kHz}$ were examined in a situation where the biological composition was simple. Method 1 used the SV difference, and Method 2 used both SV difference and body length data from net samples. The high-pass sphere model and straight cylinder model were applied depending on dominant target species: when they were relatively small, such as copepods, the high-pass sphere model was used, and when adult krill were dominant the straight cylinder model was used to take the swimming angle of the adult krill into consideration. Acoustic estimates were compared with net samples. Using the high-pass sphere model, Method 1 provided plausible estimates of zooplankton size and biomass, and Method 2 provided better biomass estimates. Furthermore, it was shown that by using the straight cylinder model and swimming angle distribution, Method 1 can be applied to obtain estimations of the krill's size and biomass.
\end{abstract}

KEY WORDS: Dual frequency method Z Zooplankton $\cdot$ Echo sounder

\section{INTRODUCTION}

Zooplankton measurements by acoustical methods have been reported by many researchers (e.g. Greenlaw 1979, Holliday \& Pieper 1980, Kristensen \& Dalen 1986, Takiguchi et al. 1988). In addition, a multifrequency method has been developed that can be used to estimate zooplankton size and biomass (Holliday et al. 1989). However, an acoustic system that makes the multifrequency method possible is not common because of high cost and complexity

In cases where the size distribution of zooplankton has only a single mode, Greenlaw (1979), Furusawa (1990) and Mitson et al. (1996) have examined a dual frequency method based on the difference in volume backscattering strength (SV) between 2 frequencies.

\footnotetext{
Present addresses:

- Laboratory of Training Ship, Faculty of Fisheries, Hokkaido University, Minato, Hakodate, Hokkaido 041-8611, Japan. E-mail: miyashi@fish.hokudai.ac.jp

-Department of Aquatic Bioscience, Graduate School of Agricultural and Life Science, The University of Tokyo, Bunkyo, Tokyo 113-8657, Japan
}

Miyashita et al. (1996a) reported a modified dual frequency method using both body length data from net samples and SV difference. At present, quantitative echo sounders with 2 frequencies are regularly mounted on research vessels. However, the dual frequency method has not been examined enough to become well established, because the problems of theoretical scattering models and swimming orientation, which influence the precision of acoustic estimates, remain. In this paper, we studied the dual frequency method using a common quantitative echo sounder system and 2 different theoretical scattering models which should be applied depending on the dominant target species.

\section{METHODS AND THEORY}

Dual frequency methods. We examine 2 kinds of dual frequency methods for zooplankton abundance estimates using the difference in SV at 2 frequencies. Method 1 uses the SV difference alone (Greenlaw 1979, Furusawa 1990, Mitson et al. 1996), and Method 2 uses both the SV difference and body length data from net samples (Miyashita et al. 1996a) 
Method 1: If the size distribution of zooplankton has only a single mode (length, $L$ ), the density of the zooplankton can be calculated as follows. The volume back-scattering coefficients $s_{\mathrm{v}}\left(f_{1}\right)$ and $s_{\mathrm{v}}\left(f_{2}\right)$ at frequencies $f_{1}$ and $f_{2}$ can be expressed as

and

$$
s_{\mathrm{v}}\left(f_{1}\right)=n \mathrm{E}\left[\sigma_{\mathrm{bs}}\left(f_{1}, L\right)\right]
$$

$$
s_{\mathrm{v}}\left(f_{2}\right)=n \mathrm{E}\left[\sigma_{\mathrm{bs}}\left(f_{2}, L\right)\right]
$$

The ratio of the volume back-scattering coefficients $s_{\mathrm{y}}\left(f_{1}\right)$ and $s_{\mathrm{v}}\left(f_{2}\right)$ is equal to the ratio of the back-scattering cross sections $\sigma_{\mathrm{bs}}\left(f_{1}, L\right)$ and $\sigma_{\mathrm{bs}}\left(f_{2}, L\right)$. The volume back-scattering coefficient is measured, and the back-scattering cross section is given by a scattering model. As a result, the ratio of $\sigma_{\text {bs }}$ values is a function of length $(L)$ of the targets, and $L$ can be calculated. Subsequently, the density (n) of the targets can be obtained from these equations.

Method 2: If the size distribution of zooplankton has only 2 modes, the volume back-scattering coefficients $s_{v}\left(f_{1}\right)$ and $s_{v}\left(f_{2}\right)$ at frequencies $f_{1}$ and $f_{2}$ can be expressed as

and

$$
s_{\mathrm{v}}\left(f_{1}\right)=n\left(L_{1}\right) \mathrm{E}\left[\sigma_{\mathrm{bs}}\left(f_{1}, L_{1}\right)\right]+n\left(L_{2}\right) \mathrm{E}\left[\sigma_{\mathrm{bs}}\left(f_{1}, L_{2}\right)\right]
$$

$$
s_{\mathrm{v}}\left(f_{2}\right)=n\left(L_{1}\right) \mathrm{E}\left[\sigma_{\mathrm{bs}}\left(f_{2}, L_{1}\right)\right]+n\left(L_{2}\right) \mathrm{E}\left[\sigma_{\mathrm{bs}}\left(f_{2}, L_{2}\right)\right]
$$

where $L_{1}$ and $L_{2}$ are mean body lengths of 2 size classes of zooplankton given from net samples, and where $f_{1}$ and $f_{2}$ are the frequencies used. Values of $s_{\mathrm{v}}\left(f_{1}\right)$ and $s_{\mathrm{v}}\left(f_{2}\right)$ are measured and $\sigma_{\mathrm{bs}}$ values are calculated from a theoretical scattering model. As a result, the densities of zooplankton $n\left(L_{1}\right)$ and $n\left(L_{2}\right)$ can be calculated from Eqs. (3) \& (4).

Theoretical scattering model. In this paper, we used 2 kinds of theoretical scattering models: the high-pass sphere model (Johnson 1977, 1978) and the straight cylinder model (Stanton 1988a,b). The high-pass sphere model was used when small zooplankton were dominant, and the straight cylinder model was used when adult krill were dominant.

The back scattering cross section $\left(\sigma_{b s}\right)$ of small zooplankton is usually modeled by the high-pass sphere model (Johnson 1977, 1978) as follows:

$$
\sigma_{\mathrm{bs}}=\frac{a_{e}{ }^{2} 2\left(k a_{e}\right)^{4}}{\left[2+3\left(k a_{e}\right)^{4}\right]} d^{2}
$$

where $a_{e}$ is the equivalent sphere radius, $k$ is the wavenumber in water, and

$$
\mathrm{d}=\frac{1-g h^{2}}{3 g h^{2}}+\frac{1-g}{1+2 g}
$$

$\mathrm{g}$ and $\mathrm{h}$ are density contrast and sound speed contrast, respectively.
In this study, we assumed $a_{e}=L / 2$, where $L$ is body length of the target organism.

Commonly, krill-like organisms can be modeled by the liquid straight cylinder model (Stanton 1988a,b), which can be formulated as follows:

$$
\sigma_{\mathrm{bs}}=\frac{L^{2}}{\pi^{2}}\left[\frac{\sin (k L \sin \theta)}{k L \sin \theta}\right]^{2}\left|\sum_{m}^{\infty} \mathrm{b}_{m}(-1)^{m}\right|^{2}
$$

where $\theta$ is the swimming angle,

$$
\mathrm{b}_{m}=\frac{-\varepsilon_{m}}{1+i C_{m}}
$$

$\varepsilon_{m}=$ Neumann number, $\varepsilon_{m}=1$ for $m=0$ and $\varepsilon_{m}=2$ for $m>0$,

$$
C_{m} \equiv \frac{\frac{J_{m}^{\prime}\left(K^{*} a_{c}\right) N_{m}\left(K a_{c}\right)}{J_{m}\left(K^{*} a_{c}\right) J_{m}^{\prime}\left(K a_{c}\right)} g h \frac{N_{m}^{\prime}\left(K a_{c}\right)}{J_{m}^{\prime}\left(K a_{c}\right)}}{\frac{J_{m}^{\prime}\left(K^{*} a_{c}\right) J_{m}\left(K a_{c}\right)}{J_{m}\left(K^{*} a_{c}\right) J_{m}^{\prime}\left(K a_{c}\right)}-g h}
$$

$\mathrm{g}=\rho^{*} / \rho, \mathrm{h}=c^{*} / c, K=k \cos \theta, K^{*}=k^{*} \cos \theta$.

In these equations, $J$ and $N$ are the Bessel functions of order $m$ of the first and the second kind, respectively, and the primes indicate derivatives with respect to their arguments. $a_{c}$ is half the krill's body length, $\rho$ and $c$ are the specific density and the speed of sound in water, and $\rho^{*}, c^{*}$ and $k^{*}$ are the specific density, speed of sound and wavenumber in krill. In this paper, the parameters $g$ and $h$ used in computations are taken from Greenlaw (1977) ( $\mathrm{g}=1.043, \mathrm{~h}=1.052)$, and the parameter $a_{c}$ is taken from a regression relationship by Miyashita (1996) $\left(a_{C}=0.0675 \mathrm{~L}\right)$.

Data collection and analysis. The data used in the analysis were collected on the RV 'Tansei-maru' cruise KT-93-6 from May 7 to 14, 1993, and the RV 'Wakataka-maru' cruise from April 12 to 18, 1996, off Sanriku, northeastern Japan. A dual frequency system 'FQ-50' (Furuno, 50 and $200 \mathrm{kHz}$ ) mounted on the RV 'Tansei-maru' and a 4 frequency system 'KFC2000' (Kaijo, 38, 70, 120, $200 \mathrm{kHz}$ ) mounted on the RV 'Wakataka-maru' were used for acoustic data collection. For the RV 'Wakataka-maru' cruise, data at frequencies of 38 and $120 \mathrm{kHz}$ were used for analysis. The parameters of both quantitative echo sounders are summarized in Table 1. In these cruises, we calibrated these echo sounder systems using a tungsten carbide ball (diameter of $38.1 \mathrm{~mm}$ ).

Zooplankton samples were collected by concurrent MTD net (Motoda 1971) or midwater trawl net tows for comparison with acoustic data. On the KT-93-6 cruise, MTD nets, with a mouth diameter of $56 \mathrm{~cm}$ and mesh aperture of $0.33 \mathrm{~mm}$, were towed for $15 \mathrm{~min}$ at 5 depth layers $(10,30,50,70$, and $90 \mathrm{~m})$. On the RV 'Wakatakamaru' cruise, a midwater trawl net, with a cover net of $8 \mathrm{~mm}$ mesh aperture and cod end of $60 \mathrm{~mm}$ mesh aper- 
Table 1. Summary of the quantitative echo sounders FQ50 and KFC 2000 used on the RV 'Tansei-maru' and RV 'Wakataka-maru' cruises, respectively, conducted off Sanriku, northeastern Japan

\begin{tabular}{|lcccc|}
\hline & \multicolumn{2}{c}{ FQ50 } & \multicolumn{2}{c|}{ KFC2000 } \\
\hline Frequency $(\mathrm{kHz})$ & 50 & 200 & 38 & 120 \\
Equivalent beam angle $(\mathrm{dB})$ & -14.5 & -16.1 & -19.1 & -19.1 \\
Pulse duration $(\mathrm{ms})$ & 1.0 & 1.0 & 1.2 & 1.2 \\
Threshold $(\mathrm{dB})$ & -99.9 & -99.9 & -99.9 & -99.9 \\
TVG $(\log R)$ & 20 & 20 & 20 & 20 \\
\hline
\end{tabular}

ture, were towed for $30 \mathrm{~min}$ or $1 \mathrm{~h}$. CTD casts were made to determine the physical parameters for calibration of acoustic data. On the KT-93-6 cruise, data from the 10 (B10) and $30 \mathrm{~m}$ (B30) depth layers at Stn B off Sendai and from the 10 (C10), 30 (C30) and $70 \mathrm{~m}$ (C70) depth layers at Stn $\mathrm{C}$ off Miyako, northeastern Japan, were used in the analysis. On the RV 'Wakataka-maru' cruise, data from the $40 \mathrm{~m}$ (W40) depth layer at Stn W-8 off Miyako, northeastern Japan, were used in the analysis.

\section{RESULTS}

Table 2 shows the zooplankton composition of the net samples taken by MTD nets at Stns B and C. Zooplankton were classified into 2 groups by body shape: (1) amphipods and copepods and (2) euphausiids. In the 3 cases $\mathrm{C} 10, \mathrm{C} 70$, and $\mathrm{B} 30$, the weight density compositions were dominated by large amphipods/copepods, small krill, and small amphipods/copepods, respectively. In the 2 cases $\mathrm{B} 10$ and C30, weight density compositions of amphipods/copepods and euphausiids were almost equal.

At Stn W-8, samples caught by midwater trawling were dominated by isada krill Euphausia pacifica and the mean body length was $16.5 \mathrm{~mm}$ $(\mathrm{SD}=1.6, \mathrm{~N}=100)$. However, the weight density of isada krill could not be calculated because the filtered volume was not determined.

Table 3 gives a summary of the estimated body length and weight density by Methods 1 and 2 in the cases of C10, C70, B30, B10 and C30. In these 5 cases, the high-pass sphere model was used, because small zooplankton were dominant in the net samples.

In the case of $\mathrm{C} 10$, the body length estimated by Method 1 was $6.9 \mathrm{~mm}$. This value was 0.9 times the mean body length of dominant amphipods/copepods $(7.9 \mathrm{~mm})$ in the net samples. However, the weight density estimated by Method 1 was $1 / 3$ of that in the net samples. The weight density of amphipods/copepods estimated by Method 2 was $1 / 4$ of that in the net samples, while the estimated density of euphausiids was 1.8 times that in the net samples.

In the cases of C70 and B30, the body lengths estimated by Method 1 were 1.4 and $0.6 \mathrm{~mm}$, respectively, longer than the mean body length of dominant organisms $(3.7 \mathrm{~mm})$ in the net samples. The weight densities estimated by Method 1 were also close to those in the net samples. The weight densities estimated by Method 2 for C70 were close to those in the net samples, but weight density of

Table 2. Organism compositions in net samples at Stns B (10 and $30 \mathrm{~m}$ depth) and $C(10,30$ and $70 \mathrm{~m}$ depth). TL: body length (SD in parentheses)

\begin{tabular}{|c|c|c|c|c|}
\hline Order & $\begin{array}{l}\text { Wet weight } \\
\text { (g) }\end{array}$ & $\begin{array}{c}\text { Averaged TL } \\
(\mathrm{mm})\end{array}$ & $\begin{array}{l}\text { Weight density } \\
\qquad\left(\mathrm{g} \mathrm{m}^{-3}\right)\end{array}$ & $\begin{array}{c}\text { Weight ratio } \\
(\%)\end{array}$ \\
\hline \multicolumn{5}{|l|}{$\mathrm{C} 10$} \\
\hline Amphipods/copepods & s 869 & $7.9(0.6)$ & 2.21 & 96.5 \\
\hline Euphausiids & 32 & $3.7(0.5)$ & 0.08 & 3.5 \\
\hline \multicolumn{5}{|l|}{$\mathrm{C} 70$} \\
\hline Amphipods/copepods & 3.2 & $10.8(2.0)$ & 0.01 & 5.4 \\
\hline Euphausiids & 56 & $3.7(0.6)$ & 0.14 & 94.6 \\
\hline \multicolumn{5}{|l|}{ B30 } \\
\hline Amphipods/copepods & 44 & $3.7(0.5)$ & 0.11 & 90.5 \\
\hline Euphausiids & 4.6 & $7.0(1.3)$ & 0.01 & 9.5 \\
\hline \multicolumn{5}{|l|}{ B10 } \\
\hline Amphipods/copepods & 58.21 & $3.7(0.5)$ & 0.15 & 50.0 \\
\hline Euphausiids & 58.84 & $7.0(1.3)$ & 0.15 & 50.0 \\
\hline \multicolumn{5}{|l|}{$\mathrm{C} 30$} \\
\hline Amphipods/copepods & 33.8 & $8.7(1.7)$ & 0.09 & 58.5 \\
\hline Euphausiids & 24 & $4.0(0.5)$ & 0.06 & 41.5 \\
\hline
\end{tabular}

Table 3. Summary of the estimated TL and weight density obtained by Methods 1 and 2 at Stns $B$ and $C$

\begin{tabular}{|c|c|c|c|c|}
\hline \multirow[t]{2}{*}{ Sample } & \multicolumn{2}{|c|}{ Method 1} & \multicolumn{2}{|c|}{ Method 2} \\
\hline & $\begin{array}{l}\text { Estimated TL } \\
\qquad(\mathrm{mm})\end{array}$ & $\begin{array}{l}\text { Weight density } \\
\qquad\left(\mathrm{g} \mathrm{m}^{-3}\right)\end{array}$ & $\begin{array}{l}\text { Amphipods/copepods } \\
\qquad\left(\mathrm{g} \mathrm{m}^{-3}\right)\end{array}$ & $\begin{array}{l}\text { Euphausiids } \\
\qquad\left(\mathrm{g} \mathrm{m}^{-3}\right)\end{array}$ \\
\hline C10 & 6.9 & 0.7 & 0.53 & 0.14 \\
\hline$C 70$ & 5.1 & 0.22 & 0.02 & 0.18 \\
\hline B30 & 4.3 & 0.13 & 0.03 & 0.02 \\
\hline B10 & 4.8 & 1.35 & 0.37 & 0.33 \\
\hline C 30 & 6.4 & 0.37 & 0.17 & 0.13 \\
\hline
\end{tabular}


Table 4. Summary for the estimated TL and weight density by Method 1 at $40 \mathrm{~m}$ depth at Stn $W-8$. When the swimming angle distribution of actively swimming krill was used, estimated TL was closest to that of the net sample $(16.5 \mathrm{~mm})$

\begin{tabular}{|lcc|}
\hline $\begin{array}{l}\text { Swimming behaviour } \\
\text { (mean swimming angle, SD) }\end{array}$ & $\begin{array}{c}\text { Estimated TL } \\
(\mathrm{mm})\end{array}$ & $\begin{array}{c}\text { Weight density } \\
\left(\mathrm{g} \mathrm{m}^{-3}\right)\end{array}$ \\
\hline Dorsal aspect $(0,0)$ & 36.5 & 0.91 \\
Actively swimming $(15.0,24.4)$ & 17.0 & 8.32 \\
Total $(30.4,19.9)$ & 21.0 & 3.47 \\
\hline
\end{tabular}

amphipods/copepods for B30 was estimated to be $1 / 4$ of that in the net samples.

In the cases of B10 and C30, the body lengths estimated by Method 1 approximated the mean body length of all the organisms in the net samples. However, the weight densities estimated by Methods 1 and 2 were a few times larger than those in the net samples. Method 2 provided better estimates than Method 1.

In the case of W40, the straight cylinder model was used, because adult krill were dominant in the net sample. The averaged TS (target strength) was calculated by the simplified method of Foote (1980) in which only the swimming angle was considered. Parameter pairs (mean, SD) of the swimming angle were used from Miyashita et al. (1996b) in which they were collected with free swimming krill in an aquarium: dorsal aspect $(0,0)$; actively swimming $(15.0,24.4)$; and total (actively swimming and hovering) $(30.4,19.9)$.

Table 4 gives a summary of the estimated body length and weight density for W40 by Method 1. As a result, when the swimming angle distribution of actively swimming krill was used, estimated body length $(17.0 \mathrm{~mm})$ was closest to that of the net sample (16.5 mm). Estimated weight densities differed considerably among 3 swimming conditions.

\section{DISCUSSION}

In the cases where the size distribution of zooplankton only had a single mode (C10, C70, B30), the estimated body length using Method 1 was similar to the mean body length of the dominant species in the net samples. Furthermore, estimated weight densities were 0.3 to 1.5 times those of the net samples. Therefore, for the above 3 cases, we conclude that these estimated values were acceptable for the acoustic estimate, and that Method 1 could be used to estimate zooplankton abundance. However, in the cases where the size distribution of zooplankton had 2 modes (B10, C30), the body length estimated by Method 1 approximated the mean body length of the net samples, which was in the middle of the 2 size modes. Furthermore the estimated weight densities were 2.5 to 4.5 times larger than those of the net samples. Here, we consider these differences to be caused by the multi-species population, or errors in the physical parameters $g$ and $h$. That is to say, Method 1 worked better on the singlesize population because it was derived for a single-size population. Errors in the choice of model and its physical parameters will affect both analyses (multi-species and single-size populations).

In the case where the size distribution of zooplankton had only a single mode (C10, C70, B30), the estimated weight densities using Method 2 were 0.3 to 1.3 times larger than those of the net samples. In the above 3 cases, the error of Method 2 was almost the same as that of Method 1. On the other hand, in the case where the size distribution of zooplankton had 2 modes (B10, C30), the estimated weight densities were 2.0 to 3.3 times larger than those of the net samples. In this case, the error of Method 2 was smaller than that of Method 1. Therefore, we suggest that Method 2 can be used to estimate zooplankton abundance. However, if the composition of organisms is more complex in the survey area, it will be impossible to estimate the zooplankton abundance by Method 2. Namely, when the size distribution of zooplankton has more than 2 modes in a survey area, estimations of zooplankton abundance cannot be calculated from Eqs. (3) \& (4). Furthermore, Method 2 requires net sample processing which is time consuming. Method 2 can hardly provide real time estimation of zooplankton abundance.

As stated above, when the adult krill were dominant (W40), acoustically estimated body length using the swimming angle distribution of actively swimming krill $(15,24.4)$ was close to that of the net sample. Isada krill are well known to swarm in the study area at the beginning of spring. When isada krill swarm, they probably swim actively. It may be suggested that we

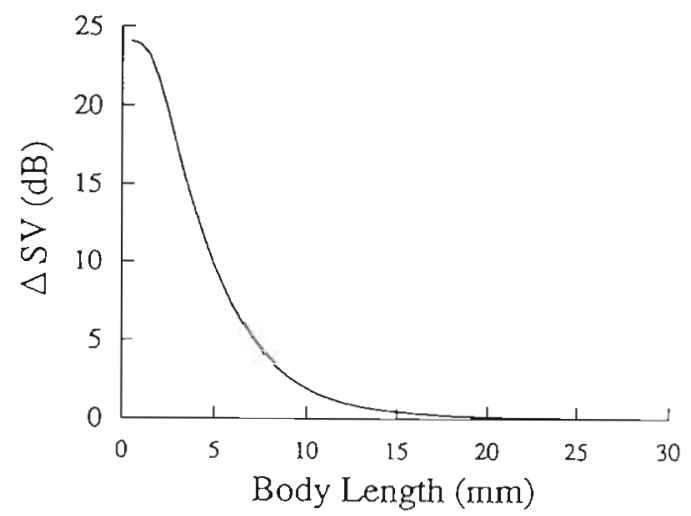

Fig. 1. Relationship between body length $(L)$ of the target organism and SV difference $\left(\Delta S V=S V_{200}-S V_{50}\right)$ calculated by the high-pass sphere model $\left(a_{\mathrm{e}}=L / 2\right)$ 
should use the swimming angle distribution of actively swimming krill for estimating the size and density of isada krill swarms. In this study, however, estimated weight densities could not be compared with those of the net sample. Individual densities of isada krill swarms were estimated by net sampling to be 2.505 to 5.123 ind. $\mathrm{m}^{-3}$ (Terazaki 1980 ) and 24 ind. $\mathrm{m}^{-3}$ (Taki 1993). These estimates show that individual density fluctuates greatly. Therefore, we need to further compare weight density from estimated acoustic data with quantitative net sampling data.

In this paper, we showed that both dual frequency methods are useful for estimation of zooplankton abundance. On the other hand, there remain some problems in estimation of zooplankton abundance. Fig. 1 shows the relationship between the size of the target organism and the SV difference $\left(\mathrm{SV}_{200}-\mathrm{SV}_{50}\right)$ calculated by the high-pass sphere model $\left(a_{\mathrm{e}}=L / 2\right)$. In Methods 1 and 2 using the high-pass sphere model, the size range of the target organism whose size we can estimate is limited, ranging from 1.0 to $10.0 \mathrm{~mm}$. That is to say, the frequency difference using the highpass sphere model is constant in the size ranges $<1.0 \mathrm{~mm}$ and $>10.0 \mathrm{~mm}$. If we want to quantify zooplankton of smaller size, a quantitative echo sounder system with higher frequencies will be needed. However, since sound absorption is larger at higher frequencies, sound does not reach to deeper depth layers (over $200 \mathrm{~m}$ ). Therefore, we will have to examine the use of a tow-body transducer which can be positioned close to the target organisms. Furthermore, the error of the estimation of zooplankton abundance may be caused by the high-pass sphere model, because maximum body length of zooplankton used in this study is close to directional scatters at $200 \mathrm{kHz}$. The high-pass sphere model is simple, but a sophisticated scattering model is better for quantification of large size zooplankton at $200 \mathrm{kHz}$.

Furusawa et al. (1994) and Miyashita et al. (1996b) reported that the scattering strength of krill-like organisms depended on their swimming behaviour. An appropriate value of the swimming angle should be used in an acoustic survey of elongated organisms such as krill. It is therefore necessary to study the swimming behaviour of krill-like organisms under various experimental conditions.

In order to make acoustic estimations of zooplankton more precise, we need to apply an appropriate scattering model corresponding to target organisms, taking into acount differences in morphology and behaviour. Therefore, we must also consider that net sampling must be performed to obtain the ground truth. It would be ideal to also include in situ direct observations of zooplankton behaviour.

Editorial responsibility: Kenneth Sherman (Contributing Editor), Narragansett, Rhode Island, USA
Acknowledgements. The authors wish to thank Dr W. Nordhausen of Scripps Institution of Oceanography, California, USA, and Dr T. Inagaki of the Ocean Research Institute, The University of Tokyo, for their useful comments. Thanks are also due to Captain Y Tanaka and the crew of RV 'Tanseimaru', and Captain Doi and the crew of RV 'Wakataka-maru', for their great help.

\section{LITERATURE CITED}

Foote KG (1980) Averaging of fish target strength functions. $\mathrm{J}$ A coust Soc Am 67:504-515

Furusawa M (1990) Study on echo sounding for estimating fisheries resources. Bull Natl Res Inst Fish Eng 11:173-249 (in Japanese)

Furusawa M, Miyanohana Y, Ariji M, Sawada Y (1994) Prediction of krill target strength by liquid prolate spheroid model. Fish Sci 60:261-265

Greenlaw CF (1977) Backscattering spectra of preserved zooplankton. J Acoust Soc A.m 62:44-52

Greenlaw CF (1979) Acoustical estimation of zooplankton populations. Limnol Oceanogr 24:226-242

Holliday DV, Pieper RE (1980) Volume scattering strengths and zooplankton distributions at acoustic frequencies between 0.5 and $3 \mathrm{MHz}$. J Acoust Soc Am 67:135-146

Holliday DV, Pieper RE, Kleppel GS (1989) Determination of zooplankton size and distributions with multifrequency acoustic technology. J Cons Int Explor Mer 46:52-61

Johnson RK (1977) Sound scattering from a fluid sphere revisited. J Acoust Soc Am 61:375-377

Johnson RK (1978) Erratum: 'Sound scattering from a fluid sphere revisited' J Acoust Soc Am 63:626

Kristensen A, Dalen J (1986) Acoustic estimation of size distribution and abundance of zooplankton. J Acoust Soc Am 80:601-611

Mitson RB, Simard Y, Goss C (1996) Use of a two-frequency algorithm to determine size and abundance of plankton in three widely spaced locations. ICES J Mar Sci 53: $209-215$

Miyashita K (1996) Study on the acoustical estimation of zooplankton distribution and abundance. Doctoral thesis, The University of Tokyo (in Japanese)

Miyashita K, Aoki I, Inagaki T (1996a) Acoustical estimation of zooplankton size and density using two-frequency methods. Nippon Suisan Gakkaishi 62:68-72 (in Japanese)

Miyashita K, Aoki I, Inagaki T (1996b) Swimming behaviour and target strength of isada krill (Euphausia pacifica). ICES J Mar Sci 53:303-308

Motoda S (1971) Devices of simple plankton apparatus V. Bull Fac Fish Hokkaido Univ 22:101-106

Stanton TK (1988a) Sound scattering by cylinders of finite length. I. Fluid cylinders. J Acoust Soc Am 83:55-63

Stanton TK (1988b) Sound scattering by cylinders of finite length. II. Elastic cylinders. J Acoust Soc Am 83:64-67

Taki K (1993) The survey results of isada krill. In: Taki K (ed) Report of the research meeting on North Pacific krill resources, No. 2. Tohoku National Fisheries Research Institute, Shiogama, p 66-70 (in Japanese)

Takiguchi N, Suzuki T, Sano N, Iida K (1988) Acoustic estimation of zooplankton density of acoustic scattering layer off the east coast of Oshima Peninsula. Bull Fac Fish Hokkaido Univ 39:11.5-123 (in Japanese)

Terazaki M (1980) Surface swarms of a euphausiid Euphausia pacifica in Otsuchi bay, northern Japan. Bull Plankton Soc Jpn 27:19-25

Submitted: May 14, 1997; Accepted: January 7, 1999

Proofs received from author(s): April 13, 1999 